\title{
An asymptomatic young woman with abnormal manubrium sterni
}

\section{Dae Hee Han • Myeong Im Ahn • Jung Im Jung •} Seog Hee Park

Published online: 30 July 2009

(C) ISS 2009

\section{History}

A 23-year-old woman recently diagnosed with nonHodgkin lymphoma underwent computed tomography (CT) of the chest as part of the initial staging work-up (Fig. 1).
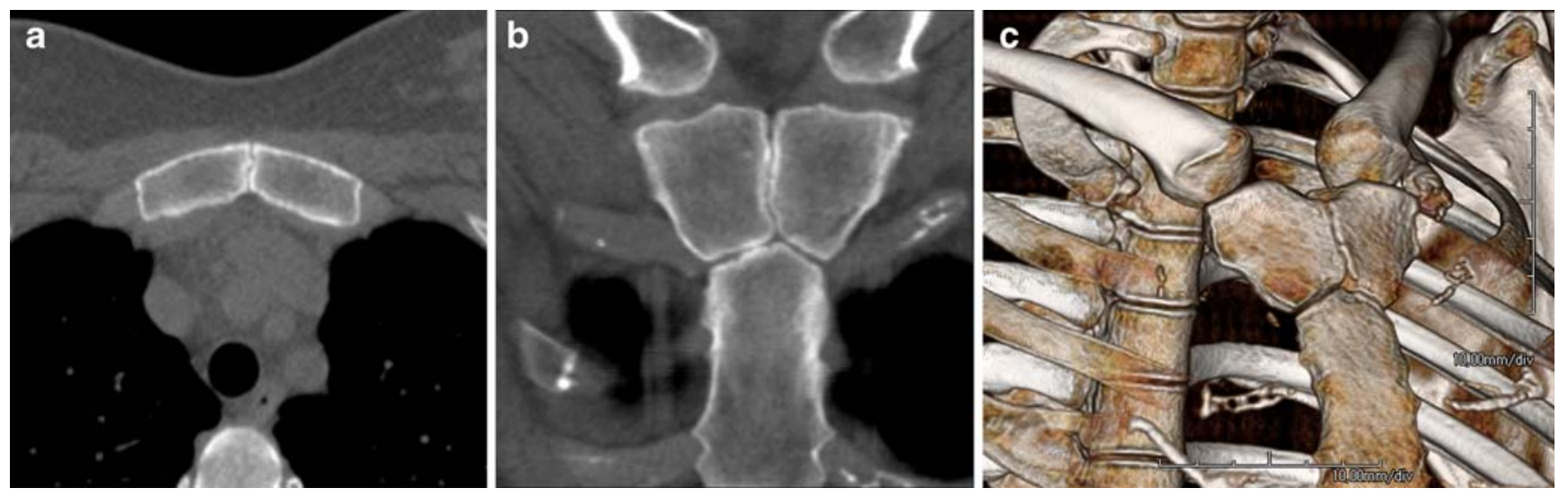

Fig. 1 a Axial CT scan through the manubrium; b oblique coronal CT reconstruction; c volume-rendering CT image with right anterior oblique projection

The diagnosis can be found at doi: 10.1007/s00256-009-0753-3.

D. H. Han • M. I. Ahn $(\varangle) \cdot$ J. I. Jung $\cdot$ S. H. Park

Department of Radiology, Seoul St. Mary's Hospital,

College of Medicine, The Catholic University of Korea,

505 Banpo-dong, Seocho-gu,

Seoul 137-701, Korea

e-mail: ami@catholic.ac.kr

D. H. Han

e-mail: lepolder@gmail.com

J. I. Jung

e-mail: jijung@catholic.ac.kr

S. H. Park

e-mail: parksh@catholic.ac.kr 